\title{
Puzzle-Based Learning in Engineering Mathematics: Students’ Attitudes
}

\begin{abstract}
The article reports on the results of two case studies on the impact of the regular use of puzzles as a pedagogical strategy in the teaching and learning of engineering mathematics. The intention of using puzzles is to engage students' emotions, creativity and curiosity and also enhance their generic thinking skills and lateral thinking “outside the box”. Students’ attitudes towards this pedagogical strategy are evaluated via short questionnaires with two groups of university students taking a second year engineering mathematics course. Students’ responses to the questionnaire are presented and analysed in the paper.
\end{abstract}

\section{Introduction and Rationale}

A significant number of tertiary engineering and mathematics students drop out from their study during the first-year not because the courses are too difficult but because, in their words, they 'are too dry and boring'. There are even such special terms as emotional disengagement and academic disinterest [1]. Interesting puzzles, paradoxes and sophisms can engage students’ emotions, creativity and curiosity and also enhance their conceptual understanding, critical thinking skills, problem-solving strategies and lateral thinking "outside the box”. By a puzzle we mean non-standard, non-routine, unstructured question presented in an entertaining way. Some authors treat a puzzle as an antithesis to a routine problem that "can be solved only through long, complex calculations, which tend to be mechanical and boring, and often drudgery for students” [2]. Often authors distinguish a puzzle and a procedural problem: “One good characteristic of puzzles is that they cannot be solved by rote; puzzles are invaluable in making students think” [3]. By a paradox we mean a surprising, unexpected, counter-intuitive statement that looks invalid but in fact is true. By a sophism we mean intentionally invalid reasoning that looks formally correct, but in fact contains a subtle mistake or flaw. Puzzles, paradoxes and sophisms have many common features. Among them: simplicity (often deceptive), an entertainment flavor, a surprise counterintuitive answer or an unexpected 
solution. For convenience, in this article, we will refer to puzzles, paradoxes and sophisms as puzzles.

Apart from the widespread belief that puzzles increase motivation there are other reasons why puzzles can be beneficial to the students. Solving puzzles can be linked to the development of professional skills. In case of engineering students Parhami [4] argues: "Many engineering problems are puzzlelike. Pieces of the puzzle are provided to engineers in the form of user/customer requirements, technological constraints, professional or industrial codes, and market realities. The engineer must then craft a product or process that either meets all these (often conflicting) demands or else provides partial solutions, with clear justification of the tradeoffs made when meeting all of the specifications is not possible...Puzzling problems are, of course, plentiful in the research arena, regardless of the discipline.” (p.263). Some famous puzzles are successfully used in the teaching of basic concepts in computer science as Marzocchi [5] argues: "Mathematics teachers introduce their students to computer science concepts that are enacted spontaneously and subconsciously throughout the solution to the Tower of Hanoi puzzle. These concepts include, but are not limited to, conditionals, iteration, and recursion” (p.814).

Another reason is to draw students' attention to and give them practice in the following aspect of job interviews. Many companies use puzzles at their job interviews to evaluate candidate's problem solving skills and select best of the best. They believe that the ability of solving puzzles relates to the creative thinking needed for solving innovative real life problems. A classic example is Microsoft: “The goal of Microsoft's interviews is to assess a general problem-solving ability rather than a specific competence...At Microsoft, and now at many other companies, it is believed that there are parallels between the reasoning used to solve puzzles and the thought processes involved in solving real problems of innovation. When 
technology is changing beneath your feet daily, there is not much point in hiring for a specific, soon-to-be-obsolete set of skills. You have to hire for general problem-solving capacity, however difficult that may be.” [6].

In a typical engineering curricula there is no space for a course on generic thinking skills. Lecturers hope that their students develop and enhance their generic thinking skills solving specific problems from the course. However, students often have difficulties in applying their problem solving skills outside a certain context, content or subject they learnt in a class. One possible reason might be that students are exposed mostly to routine problems in their assignments and tests that require an application of a known procedure or technique. In his classic book on problem solving [7] Schoenfeld found that university students tend to spend little time on planning the solutions. Instead, they quickly jump into “doing mathematics” and writing it down. For a routine problem (Schoenfeld called it an exercise) this strategy might work. But this is not the case with non-routine problems. Selden et al. [8] investigated students' difficulties in calculus and found that while solving non-routine problems above-average university engineering students often used sophisticated algebraic methods that lead them nowhere (76\% failure rate) instead of accessing the knowledge from calculus they possessed. Even worse failure rate was reported in another study on engineering university students' difficulties in solving a problem from calculus that had a "non-routine" wording [9]. About 95\% of the students (187 out of 197) failed to solve an application problem on a test mainly due to the unusual for them wording of the problem: instead of the more common formulation "find the velocity that minimizes the total cost of a journey" the question was "show that to minimize the total cost of a journey the truck should run approximately $28 \mathrm{~km} / \mathrm{h}$ ”. Many students simply did not know into what formula they should put the given answer 28. 
Fisher [10] claims: “. . . though many teachers would claim to teach their students `how to think', most would say that they do this indirectly or implicitly in the course of teaching the content which belongs to their special subject. Increasingly, educators have come to doubt the effectiveness of teaching 'thinking skills' in this way, because most students simply do not pick up the thinking skills in question.”

This article investigates engineering students' attitudes towards the regular use of puzzles as a pedagogical strategy and its possible impact on enhancing their problem solving and generic thinking skills. The main research questions are: What are students' perceptions on improving their problem solving skills by solving puzzles? What features of generic thinking skills are enhanced by solving puzzles from the students’ perspectives?

\section{Theoretical Considerations and Methodology}

In this study we use the Puzzle-Based Learning concept introduced by Michalewicz and Michalewicz [11]. The authors indicated the following criteria for a puzzle: independence (domain free); generality; simplicity; eureka factor; entertainment factor. The relationship of the Puzzle-Based Learning with the well-established Problem-Based Learning [12] and Project-Based Learning [13] concepts is illustrated in figure 1:

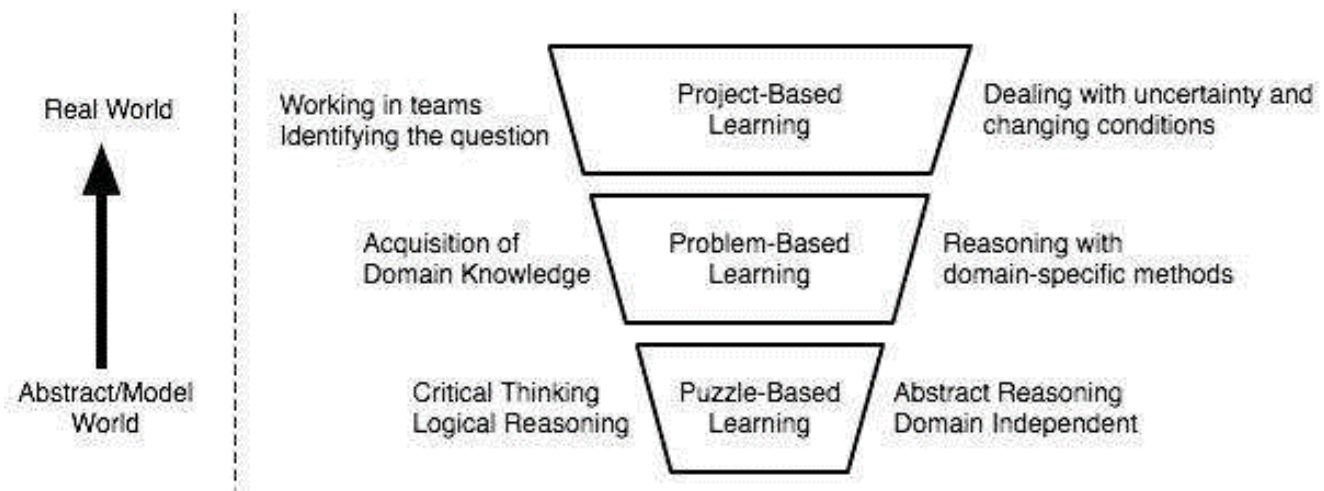

Figure 1. Relationship between different PBL concepts [14]. 
There are good discussions of the relationships between the three concepts in $[14,15]$ and between Problem-Based Learning and Puzzle-Based Learning in [3].

Falkner et al. [15] claim: “The puzzle-based learning approach aims to encourage engineering and computer science students to think about how they frame and solve problems not encountered at the end of some textbook chapter. Our goal is to motivate students while increasing their mathematical awareness and problem-solving skills by discussing a variety of puzzles and their solution strategies.” (p. 21). They are well aware that the Puzzle-Based Learning approach has a long history: "Historians found the first mathematical puzzles in Sumerian texts from circa 2500 BC. However, some of the best evidence for the puzzle-based learning approach can be found in the works of Alcuin, an English scholar born around 732 AD, whose main work, Problems to Sharpen the Young, included more than 50 puzzles.” (p.21). Such names as Henry Dudeney, Gyorgy Polya and Martin Gardner are familiar to many teachers/lecturers who use mathematical puzzles in their teaching.

What was new was the development of a formal academic course for university students devoted to the Puzzle-Based Learning. In recent years, some universities introduced courses or freshmen seminars for their first-year engineering, mathematics and computer science students based on the Puzzle-Based Learning approach as a pedagogical strategy. At some universities those courses/seminars are even compulsory. The triggers were the publication of the books $[11,16]$ and a series of conference presentations, journal articles, promotional workshops and seminars around the world by the enthusiastic authors of the two books. Preliminary feedback from those courses is promising. Falkner et al. [17] reflected on a puzzle-based course for computer science students: "The benefit to the student goes beyond the short course that they take part in, or any course-specific skills, as the lessons learnt may be applied to every other course in which they participate...The skills that they learn in puzzle-based learning are far 
more than games, as we can see when students apply these skills in their algorithmic development, their identification of test cases and their improved understanding of insufficient problem specification.” (p.267). A similar positive feedback on extensive and regular use of puzzles in the teaching of engineering mathematics is reported in [3]: "Firstly, puzzles might be recast into an engineering (or STEM) context, as discussed later, making them less abstract, more concrete, and presumably more acceptable to the typical student. Secondly, it is fortunate that many puzzles are accompanied by a diagram, or the creation of a diagram is an essential first step in finding a solution. In this aspect the procedure for solving puzzles is similar to model development and solution, and is an essential part of engineering. As far as active or reflective processing of information is concerned, the best puzzles for teaching engineers should be amenable to both approaches, although the 'eureka' moment will usually arise from reflection. If puzzles are introduced as group work, this can appeal to students with an active learning style who appreciate working with others. Finally, sets of puzzles can be selected and arranged to provide sequential learning, especially in their underlying mathematics, and an alternative is to embed puzzles in other teaching such as engineering mathematics problem classes.” (p.128). Parhami [4] successfully runs Puzzle-Based Learning seminars for computer engineering students with the aim to improve their retention rate by increasing their motivation and engagement: "We maintain that attracting students to computer science and engineering programmes, while necessary and helpful, counteracts only one aspect of the problem. Retaining and motivating students once they have chosen a computing major are other key aspects. A greater retention rate will improve the quantity and quality of our graduates much more effectively than simply admitting more students, as the latter approach would require digging deeper into the applicant pool” (p.262).

Problem-Based Learning and Puzzle-Based Learning definitely have an overlap. Barrow [18] is considered one of the first promoters of the Problem-Based Learning. He suggested the 
following six characteristics of the Problem-Based Learning: (1) student centered, (2) occurs in small groups, (3) teachers are facilitators, (4) the problems stimulate learning, (5) the problems are a vehicle for development of problem-solving skills, and (6) new information is acquired through self-directed learning. In addition, Problem-Based Learning promotes the process of inquiry and constructivist learning in the given subject area. All these features can be present in Puzzle-Based Learning especially if puzzles are given in the context of the subject/discipline that students study. When puzzles are not within a certain subject area then instead of constructing their subject content knowledge students form their collection of various problem-solving strategies and principles. Let's consider the following puzzle as an example.

A Chocolate Bar Puzzle (see for example [11]). A rectangular chocolate bar consists of $10 \times 6$ small rectangles and you wish to break it into its constituent parts. At each step, you can only pick up one piece and break it along any of its vertical or horizontal lines. How should you break the chocolate bar using the minimum number of steps (breaks)?

Unlike solving problems from the Problem-Based Learning activity where students usually know where to search for relevant information and learn new material, this puzzle is not subject specific. It is not from a textbook on mathematics or engineering or confectionery! Students need to rely on their common sense and experience. They are normally trying different approaches focusing either on the horizontal or vertical lines or alternating them. Many try calculating the number of steps for some rectangular bars of smaller sizes. The solution however is very simple if we apply the so-called invariance principle. What stays the same (invariant) after each step regardless of the breaking strategy? After the first break we have 2 pieces, after the second break we have 3 pieces, and so on. After the $k^{\text {th }}$ break we have $k+1$ pieces. So, the number of breaks is always one less than the number of pieces regardless of the 
strategy. As the final number of pieces is 60 then the total number of steps/breaks is 59 (for a $m \times n$ bar it is $m \times n-1)$. Such general problem solving principles and strategies like the invariance principle, pigeonhole (Dirichlet's box) principle, extreme principle, famous Polya’s problem solving techniques [19], start at the end, guess and check, and many others strategies used in solving puzzles can be applied by students in a variety of courses and also outside the university.

This article investigates the impact of the regular use of puzzles as a pedagogical strategy in the teaching and learning of engineering mathematics. Considering the non-routine nature of puzzles, it was anticipated that many participants of the study will be commenting on creativity using their own understanding of this concept. According to Treffenger et al. [20] there are more than 100 contemporary definitions of creativity. Shiraman and Haavold [21] claim that “creativity is a paradoxical concept because its definitions tend to be elusive for many people, yet everyone knows creativity when they see it. Numerous other contradictions are present in characterization of creativity". However, they admit that "most people tend to equate creativity with originality and 'thinking outside of the box'”. The feature of originality also presents in one way or another in many definitions used by researchers. One of the most influential theory of creativity was developed by Guilford [22] who considered creative thinking as divergent thinking based on fluency, flexibility, originality and elaboration. By fluency he meant the ability to generate great number of solutions to a problem, by flexibility the ability to suggest a variety of approaches to a problem, by originality the ability to propose unusual approaches to solve a problem, and by elaboration the ability to organize the details of an idea and implement it. Krutetskii [23] and Haylock [24] described creativity through problem formation, invention, independence, and originality. Based on Guilford model of divergent thinking Haylock [24] proposed an investigative model for mathematical creativity introducing the concept of the ability to overcome fixations to the established mental schemes in mathematical 
problem solving. Later he related creativity to flexibility of thought [25] which was similar to divergent thinking. Leikin [26, 27] introduced a practical concept of relative creativity observed in the mathematics classroom as "students' ability to produce mathematical ideas/solutions in a new situation (to a new mathematical problem that was not learned previously) or to produce original solutions to previously learned problems” [27, p.161]. She considered students' relative creativity "with respect to their own educational history and in comparison with other students... in contrast to absolute creativity which is evaluated in terms of high achievements in the creator's field and whose significance is evaluated by the professional community that regards it as a meaningful creation from an historical perspective.” (p.161). In this study, Guilford's model of creativity [22] based on divergent thinking is used as the theoretical framework with some links to Haylock’s investigative model of creativity [24, 25] based on overcoming fixations.

The case study approach in this study was chosen due to the practicality and possibility to use both quantitative and qualitative analysis of the data to answer the research questions. Two sequential case studies were conducted in 2015 and 2016 at a large $(25,000+)$ New Zealand university with two groups of second year students studying engineering mathematics course. The course was primarily on multivariate calculus. Due to a course sharing arrangement the lecturer taught only half a semester (6 weeks) in each of the one semester second-year engineering mathematics course. The lecturer offered students 2-3 puzzles every week. The puzzles were normally given to the students in the end of the first hour of a two-hour lecture. The students had a choice to solve them either individually or in pairs or small groups with their neighbours. The discussion of the solutions took place either immediately after that or in the beginning of the second hour of the lecture. After 6 weeks of the regular use and discussions of the puzzles the students in both groups were given questionnaires. The questionnaires were short and deliberately included the vague concept of 'generic thinking skills' to check students' 
interpretation of it in terms of solving puzzles. Apart from the questionnaires, there were also class observations reported by the experienced lecturer (37-year experience teaching university mathematics in different countries). The participants were chosen using a combination of two non-random sampling methods - convenience and judgement methods. The participation in both studies was voluntary. In the first case study the response rate was 95\% (62 responses out of 65 students) and in the second case study the response rate was 96\% (93 responses out of 97 students). The case studies were considered as pilot studies to investigate students' attitudes towards the regular use of puzzles in engineering mathematics.

\section{The Case Studies}

Most of the puzzles offered to the students did not require any special knowledge. Some puzzles required knowledge of simple school mathematics like the formula for an average speed. A few puzzles however did require knowledge of the basic concepts (not formulas and techniques) from the prerequisite single variable calculus course so it was partly a revision of some important calculus concepts. Below are three examples of the puzzles used in the lecturers.

\section{Examples of the Puzzles}

Puzzle: An Average Speed (see for example [11]). Suppose that you drive from A to B at a constant speed of $40 \mathrm{~km} / \mathrm{h}$. What should your constant speed be for the return trip from B to A if you want to obtain the average speed of $80 \mathrm{~km} / \mathrm{h}$ for the whole trip?

Although it can be treated as a routine problem that is easily solved by the familiar formula for the average speed the answer is so counterintuitive that the vast majority of the students did not believe it until they did calculations. As one can imagine the most common wrong answer was $120 \mathrm{~km} / \mathrm{h}$. The students were amazed to see that it is impossible to reach the average speed 
of $80 \mathrm{~km} / \mathrm{h}$ for the whole trip even if one can drive back from B to A with the speed of light. They were surprised to encounter the concept of infinity in a very practical situation that deals with the 'good' numbers like $40 \mathrm{~km} / \mathrm{h}$ and $80 \mathrm{~km} / \mathrm{h}$.

Paradox: Torricelli's Trumpet (see for example [28]). There is not enough paint in the world to paint the infinite area bounded by the curve $y=\frac{1}{x}$, the $x$-axis, and the line $x=1$ :

$$
\int_{1}^{\infty} \frac{1}{x} d x=\lim _{b \rightarrow \infty}(\ln b-\ln 1)=\infty .
$$

However, one can rotate the area around the $x$-axis and the resulting solid of revolution would have a finite volume of $\pi$ cubic units:

$$
\pi \int_{1}^{\infty} \frac{1}{x^{2}} d x=-\pi \lim _{b \rightarrow \infty}\left(\frac{1}{b}-\frac{1}{1}\right)=\pi
$$

One can fill the solid with $\pi$ cubic units of paint and thus cover the cross-section area with paint.

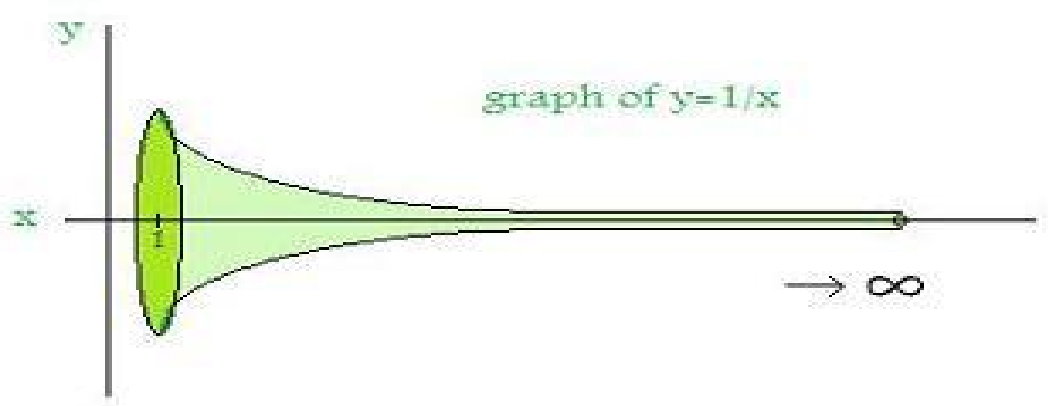

Figure 2. Diagram for the Torricelli's Trumpet paradox.

The paradox demonstrates a fundamental difference between the 'mathematical' universe and the 'physical' universe that enlightens many students. A short discussion with the students 
leads to the understanding that from a mathematical point of view one 'abstract' drop of paint is enough to cover any area, no matter how large. One just needs to make the thickness of the cover very thin. So mathematically one can cover any infinite area with any finite amount of paint, even with a single drop. In reality such infinite areas don't exist, nor can one make the cover infinitely thin.

Sophism: An Infinitely Fast Fall (see for example [28]). Imagine a cat sitting on the top of a ladder learning against a wall. Suppose that the bottom of the ladder of the length $l$ is being pulled away from the wall horizontally at a uniform rate $x^{\prime}$. The relationship between the vertical and horizontal distances from the ends of the ladder to the corner at time $t$ is expressed by the Pythagoras Theorem: $y(t)=\sqrt{l^{2}-x^{2}(t)}$. We can 'prove' that the cat speeds up, until eventually falling infinitely fast:

$$
\lim _{x \rightarrow l} y^{\prime}=\lim _{x \rightarrow l}\left(-\frac{x x^{\prime}}{\sqrt{l^{2}-x^{2}}}\right)=-\infty
$$

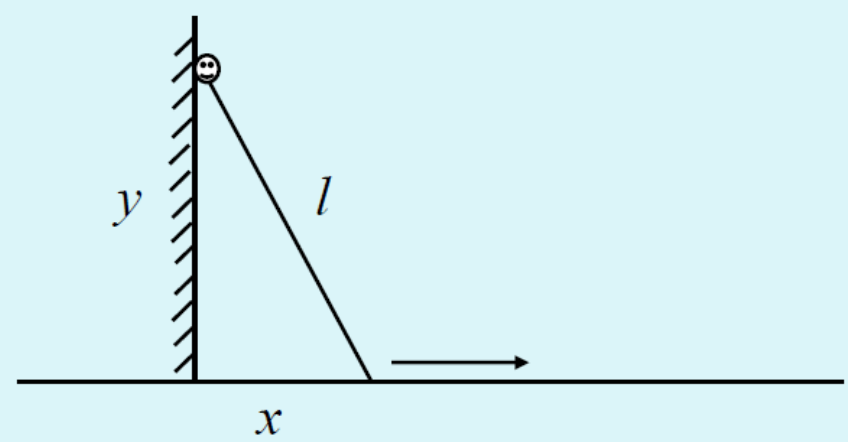

Figure 3. Diagram for the Infinitely Fast Fall sophism.

Students normally check all calculations and are surprised that they are correct. The sophism illustrates the importance of making correct assumptions when solving application problems. The 'proof' assumes that the ladder maintains contact with the wall while being pulled. Very 
few students realise that the model is not true. If all forces involved are considered it can be shown that at one stage (approximately at one-third down) the top of the ladder will lose contact and be pulled away from the wall. From that moment the relationship is no longer true, since we don’t have a right-angled triangle.

\section{Case Study 1}

The basic statistics and typical students' responses to the questionnaire are below:

Question 1. Do you feel confident solving puzzles? Please give the reasons.

Yes - 69\% "I have fair idea at times; because I am smart; because I can; I am good at problem solving; I love solving puzzles”.

No - 31\% "I overthink the problems; I need more examples to understand the way how to do the question; too hard; can get confusing; I feel that there will always be a catch; I tend to overthink and overcomplicate everything; I am constrained by knowledge taught by school system”.

Question 2. Can solving puzzles enhance your problem solving skills?

Yes $-98 \%$ In which way?

"Helps your brain to think more logically and becomes challenging; make you look at problems from different angles; broadens mind for alternative solutions; think in a different perspective, outside the box; showing that thinking differently can have amazing results; make me think creatively, not always relying on conventional/trained ways of problem solving; puzzles place an emphasis on HOW you tackle the problem; ability to think with multiple perspectives; it allows me to come to a solution faster". 
No - 2\% Why not? “Too different”.

Question 3. From you point of view, what are the main differences between puzzles and routine problems/questions?

"Puzzles are more fun to solve; more enjoyable and interesting; puzzles are more challenging because of the flexibility in approaching; puzzles require creative thinking and more careful reading; puzzles add a bit more variety; are more tricky, freshen up your mind; puzzles require more insight, creativity; more thinking and novel solutions; puzzles aren't always straight forward, some people just can't get them no matter what; a puzzle requires us to throw away those old/stubborn stuff in my brain in order to solve it; puzzles relate to more realistic things; puzzles are exciting and help to keep me alert; puzzles set a more fun environment compared to routine problems; puzzles test your problem solving skills and routine problems are testing if you can follow problems”.

\section{Case Study 2}

The basic statistics and typical students' responses to the questionnaire are below:

Question 1. Can solving puzzles enhance your problem solving skills?

Yes $-97 \%$ In which way?

"Gets you to think outside the box ( $>30)$; being able to approach questions differently $(>20)$; when it comes to solving practical problems in life $(>20)$; promotes learning using realistic situations (>10); you develop a more logically wired brain and you think about problems more open-mindedly ( $>10$ ); forces you to think creatively; it develops creative thinking which is important when facing non-standard exam questions $(>5)$; these problems relate to problems engineers may come across in real life, and solving them is good experience (>5)”. 
No $-3 \%$ Why not?

“They don’t help learning”

Question 2. Can solving puzzles enhance your generic thinking skills?

Yes $-97 \%$ In which way?

"By making you think about different situations in alternative ways (>20); it is about learning to think logically and methodically (>10); it will make students think about their theoretical solution and compare it with real world situations ( $>10)$; use creative part of brain to decide on best answer; they are just really good at getting you to think creatively ( $>5)$; you tend to see everyday life as puzzles you can solve ( $>5)$; makes you think in practical ways $(>5)$.

No - 3\% Why not?

"Puzzles can be confusing”.

Question 3. Can you see any other benefits for you in solving puzzles?

Yes $-82 \%$ What are they?

"It is a kind of fun break from the lecture which can help me concentrate; a break from the serious stuff; creating a fun learning environment; makes maths fun; allows a mini pause; it is a nice break from the current material, and acts as a nice mental break during lectures; good way to escape doing triple integrals; helps relax mind to perform better ( $>20)$; gets you thinking and involved; engage the class more than standard maths questions $(>10)$; you can use these new and different methods of thoughts in other subjects and aspects of life $(>5)$; relates to real life; life is all about solving puzzles $(>5)$; helps with visualization and general articulation of problems (3); possibly social interaction/team working (3); it gives you 
a sense of accomplishment; learning patience/perseverance; you learn to filter out the useful, relevant info from the pointless; not being constrained in plugging numbers into equations; it will come later in practical situations”.

No $-18 \%$ Why?

“The main benefits are given in questions 1 and 2; already covered in other subjects; don't learn basic maths techniques; puzzles may tend to throw off people even though it's an excellent method of testing; maybe - too tired to think”.

\section{Discussion and Conclusion}

In Case Study 1 about two thirds of the participating students reported that they were confident in solving puzzles and one third that they were not. Almost all students (98\%) believed that solving puzzles enhances their problem solving skills. The vast majority of the students expressed views on the difference between a puzzle and a routine problem similar to the authors of books/articles on Puzzle-Based Learning.

In Case Study 2 almost all participants believed that solving puzzles enhanced their problem solving skills (97\%) and generic thinking skills (97\%). Most participants (82\%) indicated other benefits for them apart from enhancing problem solving and generic thinking skills. The most common benefit is illustrated by the following comments: "a nice fun break from the serious stuff”, "helps relax mind to perform better”, “good way to escape doing triple integrals”.

The majority of the participants' favourable comments on enhancing their problem solving and generic thinking skills by solving puzzles (around 80\%) were related to creativity. Obviously, students' comments on creativity can be referred to what Leikin called 'relative creativity' [26, 27] or what Sriraman [21] called “ordinary, or everyday creativity (or little c)" as opposed to “extraordinary creativity (or big C) that refers to exceptional knowledge or products that 
change our perception of the world.” The participants connected the relatively clear concept of problem solving skills and the vague concept of generic thinking skills with such features of creativity as originality, flexibility and divergent thinking from Guilford model of creativity [22] and with 'overcoming fixations' and flexibility of thought from Haylock model [24, 25]. Commenting on different aspects of creativity the students used their own wordings like the responses below.

Typical comments on originality: "thinking outside the box" (the far most frequent comment in both case studies), "have to think outside the square", "puzzles require thinking outside the box and based on knowledge which is not always learnt in courses”, “it's always good to learn outside the box methods", "puzzles require novel solutions", "puzzles encourage lateral thinking and creative problem solving as opposed to the classic approach of mathematics", "it can train the brain to see unseen solutions”.

Typical comments on flexibility: "make you look at problems from different angles”, “puzzles teach you to look at problems from different points of views", "showing that thinking differently can have amazing results”, "being able to approach questions differently”, "taking different approaches to problems", "puzzles show the many perspectives a problem can be approached from”, “puzzles provide insight into different ways of thinking”, “by making you think about different situations in alternative ways", "think in a different perspective”, "shows things in a different aspect”, “ability to think with multiple perspectives”, “makes you think differently", "motivate thinking of multiple possibilities", "it encourages you to think in a different way to the regular mathematics course”.

Typical comments of overcoming fixations: “a puzzle requires us to throw away those old/stubborn stuff in my brain in order to solve the problem”, "using content knowledge can make finding a solution to a puzzle impossible”, "approach problems with an open mind”, 
"broadens mind to alternative solutions", "having good knowledge on how to solve problems in a wide range”, “you develop a more logically wired brain and you think about problems more open-mindedly”, "puzzles are designed to broaden your knowledge on certain fields of study”, “open mind for all possible answers”, “often, puzzles are unrelated to the course and require us to step back and think in a broader scale", "it makes me think from all aspects in order to solve it”.

Typical general comments on creativity: "it develops creative thinking which is important when facing non-standard exam questions”, “the puzzles have simple maths but require more insight and creativity to solve", "make me think creatively, not always relying on conventional/trained ways of problem solving”, "they are just really good at getting you to think creatively”, “forces you to think creatively”, “creative thinking of problem solving”, “use creative part of brain to decide on best answer”, "puzzles need creativity to solve”, "puzzles provide the opportunity to find creative answers", "puzzles are just really good at getting you to think creatively”, "challenges you to think creatively”.

Clearly, the participants expressed their perceived values of the impact of Puzzle-Based Learning on enhancing their problem solving and generic thinking skills. Despite it was just their perception and attitudes, the high proportions of positive responses in both case studies (98\% and 97\%) encourages to continue investigation of the effectiveness of Puzzle-Based Learning as a pedagogical strategy in engineering mathematics, in particular in relation to creativity. A collection of engaging puzzles, paradoxes and sophisms in calculus that can be used in teaching engineering mathematics can be found in [28].

According to Plato “all learning has an emotional base”. It was expected that students would write more about their emotions taking into account the surprising and entertaining nature of the puzzles. In fact, very little was written on emotions. However, class observations revealed 
that after seeing the correct solution to a puzzle many students in both groups expressed their various emotions ranging from surprise to astonishment and admiration. A similar observation was reported by Koichu [29] who gave his university students an engaging puzzle and described their reactions after they saw the simple solution: "With no exceptions, the presentation of this solution evokes a strong emotional feeling... simply put, they nearly cry: How could I miss such a simple solution?” (p. 258). Roth [30] claims “the related concepts of surprise, astonishment, and admiration refer to phenomena through which the person acknowledges the encounter with the absolutely new, the alien, the unanticipated”. Those students might develop or enhance their passion for mathematics according to Roth [30]: “To have a passion for a cultural practice such as mathematics, to find oneself in admiration of mathematics, requires a culture of astonishment, a culture that supports exposure to the unknown and unexpected. There has to be the possibility that even having been wrong or having had an inappropriate conception may be experienced with positive affect and, therefore, as a positive surprise: astonishment.” And along with passion for mathematics the students can enhance their mathematical thinking that "is provoked by contradiction, tension and surprise" according to Mason et al. [31]. On a practical note, "puzzles appeal to our impulse to make sense of the world, but most importantly the indulge our intellectual playfulness. Yet no matter how frivolous or contrived they are, the strategies we use to solve them expand our armoury for tackling other challenges in life” [32].

Another observation by the lecturer revealed that many students who successfully solved the puzzles were not among the top achieving students in the room. This is consistent with the comment by Koichu [29] who did a similar activity on puzzles with many university students over the years. He reported that a student who found a simple elegant solution to a puzzle is "not necessarily the most experienced or mathematically knowledgeable participant". Mamona-Downs and Downs [33] suggest that the ability to apply knowledge is as important 
as the knowledge itself. They warn: "Naively speaking, the more you know the more you can do. However, inserting knowledge within one's problem solving processes is far subtler than it might seem. Further, this issue might be a particularly troublesome one for education researchers to analyse” (p. 394). Mann [34] gives a similar warning in relation to creativity: "By applying learned strategies, a student can systematically apply multiple methods to solve a problem but never diverge into a creative strategy, never exploring areas outside the individual's known content-universe. To encourage the development of mathematical creativity, educators need to enable creative exploration and reward students who seek to expand their content-universe.” (p. 239).

It is too early to make conclusions about the effectiveness of the regular usage of puzzles in teaching mathematics or engineering courses. Falkner et al. [17] admit: "Puzzle-based learning is an experiment in progress and, like any experiment, we are still establishing how to modify our experimental protocol to truly measure the outputs. The goal is to foster general domain independent reasoning and critical thinking skills that can lay a foundation for problem-solving in future course work. As fun as puzzles inherently are, they are just a means to this pedagogical end. Our preliminary experience in different contexts has been encouraging and well received as we continue to explore this approach”. (p. 266). Thomas et al. [3] also agreed: "Puzzle-based Learning is under-used in the teaching of mathematics to engineers. It is argued here that embedding puzzles in the teaching of other subjects enhances students' learning by developing their problem-solving and independent-learning skills, whilst increasing their motivation to learn mathematics.” (p.122). According to Thomas et al. [3] the future implementation of the Puzzle-Based Learning approach in the teaching of engineering mathematics can be "either through bespoke courses as suggested and implemented by Michalewicz \& Michalewicz [11] or by redrafting puzzles into an appropriate engineering context and embedding them alongside 
exercises and problems in traditional teaching. Given curriculum constraints, the latter may be more practical.” (p.128).

The main objective is quite simple. As Falkner et al. [15] put it: "the ultimate goal of puzzlebased learning is to lay a foundation for students to be effective problem solvers in the real world”.

The presented studies were pilot studies and there was a concern that some students would complain about taking time from teaching the 'real' content. Nobody complained! Students' comments give confidence to continue with this pedagogical strategy. As future directions it would be interesting to measure students’ creativity before and after Puzzle-Based Learning activities; evaluate the relationship between the ability in solving puzzles and course performance; investigate the effect of using puzzles on student engagement, in particular attendance; analyse the impact of using puzzles on a student decision to continue their study (retention); assess students' attitudes using attitudes scales; measure the cognitive dimension of the student engagement (investment in learning, perseverance in the face of challenges, and use of deep rather than superficial strategies).

\section{References}

[1] Blondal, K. S., and Adalbjarnardottir, S. (2012). Student disengagement in relation to expected and unexpected educational pathways. Scandinavian Journal of Educational Research, 56(1), 85-100.

[2] Gnadig, P., Honyek, G., \& Riley, K. (2001). 200 puzzling physics problems, with hints and solutions. Cambridge, UK: Cambridge University Press.

[3] Thomas, C., Badger, M., Esther Ventura-Medina, E. \& Sangwin, C. (2013). Puzzle-based learning of mathematics in engineering, Engineering Education, 8(1), 122-134. 
[4] Parhami, B. (2008). A puzzle-based seminar for computer engineering freshmen, Computer Science Education, 18:4, 261-277.

[5] Marzocchi, A.S. (2016). Using the Tower of Hanoi puzzle to infuse your mathematics classroom with computer science concepts. International Journal of Mathematical Education in Science and Technology, 47 (5), 814-821.

[6] Poundstone, W. (2000). How Would You Move Mount Fuji? Microsoft's Cult of the Puzzle-How the World's Smartest Companies Select the Most Creative Thinkers. Little Brown and Company.

[7] A. Schoenfeld. (1985). Mathematical Problem Solving. Academic Press, New York.

[8] A. Selden, J. Selden, S. Hauk, and A. Mason. (2000). Why can’t calculus students access their knowledge to solve non-routine problems? In Research in Collegiate Mathematics Education, Vol. 4, A. Schoenfeld, J. Kaput, and E. Dubinsky, eds., AMS (American Mathematical Society), Washington, DC, pp. 128-153.

[9] Klymchuk, S., Zverkova, T., Gruenwald, N., \& Sauerbier, G. (2010). University students' difficulties in solving application problems in calculus: Student perspectives. Mathematics Education Research Journal (MERJ), 22(2), 81-91.

[10] Fisher, A. (2001). Critical Thinking: An Introduction, Cambridge, UK: Cambridge University Press.

[11] Michalewicz, Z. \& Michalewicz, M. (2008). Puzzle-Based Learning: An introduction to critical thinking, mathematics, and problem solving. Hybrid Publishers.

[12] Bransford, J., Sherwood, R., Vye N. \& Rieser, J. (1986). Teaching thinking and problem solving: Research foundations, American Psychologist, 41, 1078-1089. 
[13] Blumenfeld, P., Soloway, E., Marx, R., Krajcik, J., Guzdial, M. \& Palincsar, A. (1991). Motivating project-based learning: Sustaining the doing, supporting the learning, Educational Psychologist, 26 (3\&4), 369-398.

[14] Falkner, N., Sooriamurthi, R., \& Michalewicz, Z. (2012). Teaching puzzle-based learning: Development of basic concepts. Teaching Mathematics and Computer Science, 10 (1), 183-204.

[15] Falkner, N., Sooriamurthi, R. \& Michalewicz, Z. (2010). Puzzle-based learning for engineering and computer science. IEEE Computer 43 (4), 20-28.

[16] Meyer, E.F., Falkner, N., Sooriamurthi, R., \& Michalewicz, Z. (2014). Guide to Teaching Puzzle-Based Learning. Springer.

[17] Falkner, N., Sooriamurthi, R., \& Michalewicz, Z. (2012). Teaching puzzle-based learning: Development of transferable skills. Teaching Mathematics and Computer Science, 10 (2), 245268.

[18] Barrows, H.S. (1996). Problem-based learning in medicine and beyond: a brief overview. New directions for teaching and learning (68), 3-13.

[19] Polya, G. (1957). How to solve it. Garden City, NY: Doubleday and Co., Inc.

[20] Treffinger, D. J., Young, G. C., Selby, E. C., \& Shepardson, C. (2002). Assessing creativity: A guide for educators (RM02170). Storrs: University of Connecticut, The National Research Center on the Gifted and Talented.

[21] Sriraman, B., \& Haavold, P. (2017). Creativity and giftedness in mathematics education: A pragmatic view. In J. Cai (Ed.), First compendium for research in mathematics education. Reston: National Council of Teachers of Mathematics.

[22] Guilford, J. P. (1959). Traits of creativity. In H. H. Anderson (Ed.), Creativity and its 
cultivation (pp. 142-161). New York: Harper \& Brothers Publishers.

[23] Krutetskii, V. A. (1976). The psychology of mathematical abilities in school children. (J. Teller, trans. \& J.Kilpatrick \& I. Wirszup, Eds.). Chicago: University of Chicago Press.

[24] Haylock, D. (1987). A framework for assessing mathematical creativity in school children, Educational Studies in Mathematics, 18(1), 59-74.

[25] Haylock, D. (1997). Recognizing mathematical creativity in school children. International Reviews on Mathematical Education, 29(3), 68-74.

[26] Leikin, R. (2009). Exploring mathematical creativity using multiple solution tasks. In R. Leikin, A. Berman, \& B. Koichu (Eds.), Creativity in mathematics and the education of gifted students (pp. 129-145). Rotterdam: Sense Publishers.

[27] Leikin, R. \& Pitta-Pantazi (2013). Creativity and mathematics education: The state of the art. ZDM - The International Journal on Mathematics Education, 45(2), 159-166.

[28] Klymchuk, S., \& Staples, S. (2013). Paradoxes and Sophisms in Calculus. USA: Mathematical Association of America.

[29] Koichu, B. (2016). On the relationships (relatively) advanced mathematical knowledge and (relatively) advanced problem-solving behaviours. International Journal of Mathematical Education in Science and Technology, 41 (2), 257-275.

[30] Roth, W-M. (2016). Astonishment: a post-constructivist investigation into mathematics as passion. Educational Studies in Mathematics. Published online 22 October.

[31] Mason, J., Burton, L., \& Stacey, K. (2010). Thinking Mathematically. ${ }^{\text {nd }}$ edition. Pearson. [32] Bellos, A. (2016). Can You Solve My Problems? A Casebook of Ingenious, perplexing and Totally Satisfying Puzzles. London: Guardian Faber Publishing. 
[33] J. Mamona-Downs and M. Downs. (2005). The identity of problem solving, J. Math. Behav. (24), pp. 385-401.

[34] Mann, E. (2006). Creativity: The essence of mathematics. Journal for the Education of the Gifted, 30(2), 236-260. 